Check for updates

Cite this: Chem. Commun., 2018, 54, 12875

Received 13th September 2018, Accepted 19th October 2018

DOI: $10.1039 / \mathrm{c} 8 \mathrm{cc} 07444 \mathrm{e}$

rsc.li/chemcomm

\section{Room temperature methoxylation in zeolite H-ZSM-5: an operando DRIFTS/mass spectrometric study $\dagger$}

\author{
Santhosh K. Matam, (D) *ab Russell F. Howe, (D) ${ }^{c}$ Adam Thetford ${ }^{\mathrm{ab}}$ and \\ C. Richard A. Catlow ${ }^{\text {abd }}$
}

At high loading, methanol reacts under ambient conditions with acidic hydroxyls of H-ZSM-5 to methoxylate framework oxygen; while a significant proportion remains hydrogen bonded to the framework with a protonated geometry. The findings not only explain the data which have been published so far, but also pave a way forward for potential unravelling of the initial reaction steps in the relevant chemical processes.

Methoxylation is a key intermediate step for hydrocarbon synthesis through alkylation in different petro- and fine chemical processes, especially methanol to gasoline, catalysed by the zeolite ZSM-5. ${ }^{1-7}$ However, there remain many uncertainties concerning the methoxylation reaction (eqn (1)) in this catalyst. ${ }^{4-11}$

$$
\mathrm{CH}_{3}-\mathrm{OH}+\mathrm{Z}-\mathrm{OH} \rightarrow \mathrm{Z}-\mathrm{OCH}_{3}+\mathrm{H}_{2} \mathrm{O}
$$

Spectroscopic studies, mainly by solid state nuclear magnetic resonance (NMR) and infrared (IR), suggest that methoxylation occurs only at elevated temperatures $\left(>150{ }^{\circ} \mathrm{C}\right) \cdot{ }^{9-11}$ Moreover, IR studies to date appear to indicate that, under ambient conditions, methanol forms only hydrogen bonded species ${ }^{12}$ in line with which, several computational studies have suggested that methoxylation could have a significant activation energy and hence require higher temperatures. ${ }^{11,13,14}$ However, simulations also suggest decreased energy barrier for methoxylation with more than one methanol molecule per unit cell ${ }^{6,11,13-18}$ and also hint at the influence of other factors, such as the local reaction environment in the zeolite pores or the reaction conditions, on methoxylation. ${ }^{11,13}$ Interestingly, inelastic neutron scattering (INS) studies showed the occurrence of methoxylation at room temperature (RT), with,

\footnotetext{
${ }^{a}$ Department of Chemistry, University College London, London, WC1E 6BT, UK

${ }^{b}$ The UK Catalysis Hub, Research Complex at Harwell, Rutherford Appleton

Laboratory, OX11 OFA, UK. E-mail: santhosh.matam@rc-harwell.ac.uk;

Web: http://www.ukcatalysishub.co.uk/

${ }^{c}$ Chemistry Department, University of Aberdeen, AB24, UK

${ }^{d}$ Cardiff Catalysis Institute, School of Chemistry, Cardiff University, CF10 3AT, UK

$\dagger$ Electronic supplementary information (ESI) available: DRIFTS spectra of the dehydrated H-ZSM-5. See DOI: 10.1039/c8cc07444e
}

however, no indication of hydrogen bonded methanol in ZSM-5 pores. ${ }^{8}$ The INS study on the one hand substantiates the reduced energy barrier for methoxylation as indicated by simulations, and on the other hand leaves the issue still for debate due to the failure to detect hydrogen bonded species, which are observed by IR. The latter could be related to the sensitivity of the INS technique. The present study addresses this key problem by applying operando diffuse reflectance infrared Fourier transformed spectroscopy (DRIFTS) and mass spectrometry (MS) which simultaneously capture the methoxylation reaction by probing surface adsorbed species and reaction products, respectively.

We find that the dehydration of H-ZSM-5 resulted in well resolved characteristic $\mathrm{O}-\mathrm{H}$ stretching bands between 3750 and $3550 \mathrm{~cm}^{-1}$ while, zeolite framework modes (overtone and combination modes) dominate the spectrum below $2000 \mathrm{~cm}^{-1}$ (Fig. S1 of ESI $\dagger$ ). The band at $3736 \mathrm{~cm}^{-1}$ is attributed to silanol groups on the external surface of the zeolite, while the band at $3600 \mathrm{~cm}^{-1}$ is assigned to Brønsted acidic hydroxyls. ${ }^{19,20}$ The band at $3650 \mathrm{~cm}^{-1}$ is often ascribed to $\mathrm{Al}-\mathrm{OH}$ groups. ${ }^{20}$

DRIFTS difference spectra of zeolite ZSM-5 with a methanol pulse of 7 molecules per acidic site injected at RT, which is similar to our earlier INS study, ${ }^{8}$ are shown in Fig. 1. In agreement with earlier IR studies, we see that the spectra are dominated by hydrogen bonded methanol species that are unambiguously characterised by the triplet (Fig. 1A), which falls between 1500 and $3500 \mathrm{~cm}^{-1,12,19}$ plus the corresponding $\mathrm{CH}$ stretching modes of this species. The region below $1500 \mathrm{~cm}^{-1}$ does provide additional insight. However, a potential contribution from the framework modes to difference spectra needs to be considered for bands below $1500 \mathrm{~cm}^{-1}$. A negative band at $871 \mathrm{~cm}^{-1}$ followed by positive bands at around 937, 990-1000, 1185 and $1285 \mathrm{~cm}^{-1}$ are present, besides gas phase methanol P-Q-R bands between 1012 and $1050 \mathrm{~cm}^{-1}$ (Fig. 1B and Table S1, ESI $\dagger$ ). The negative band at $871 \mathrm{~cm}^{-1}$ suggests the reaction of methanol with the acid sites to form methoxy groups. ${ }^{19}$ The bands at 937 and $1185 \mathrm{~cm}^{-1}$ evolved with time not only regarding intensity but also with the position of the bands under He flow for $30 \mathrm{~min}$. The band at $937 \mathrm{~cm}^{-1}$ is assigned 


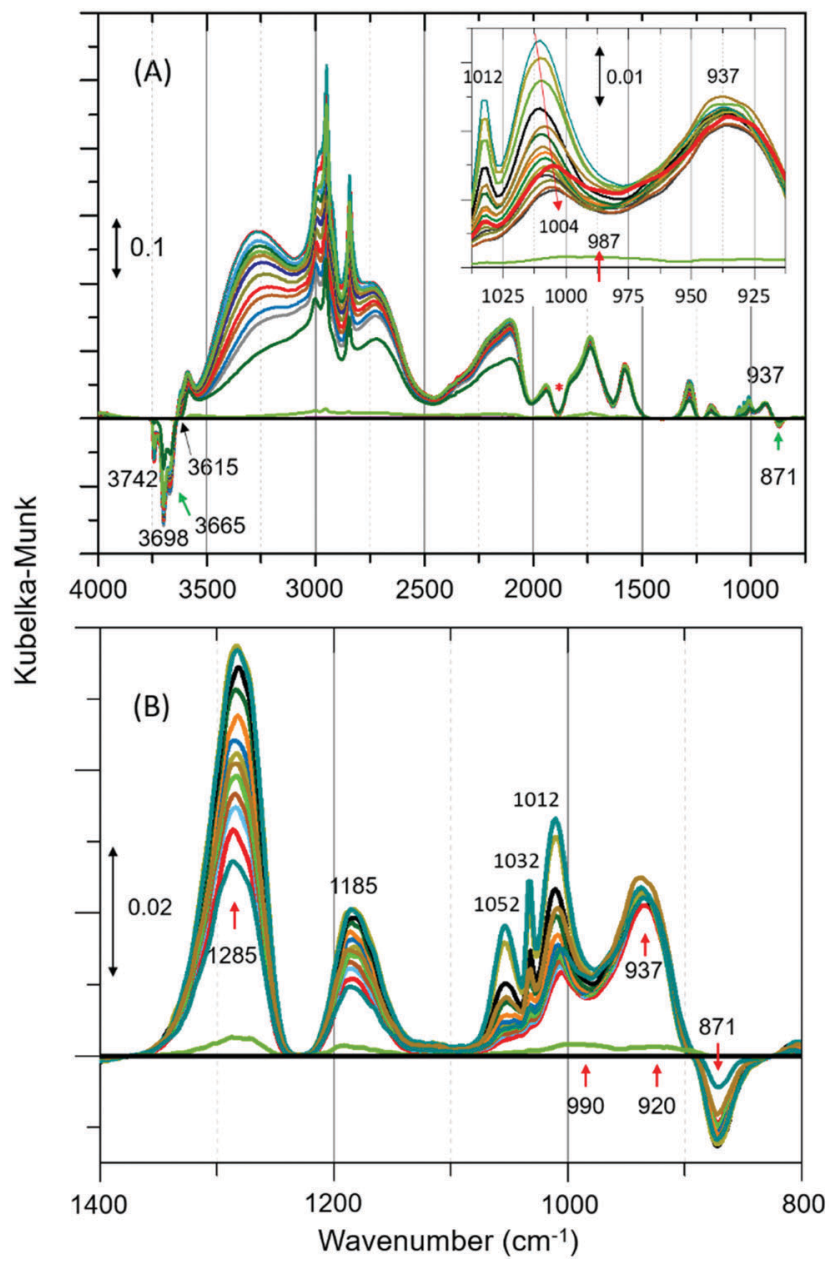

Fig. 1 (A) Selected infrared difference spectra of zeolite ZSM-5 with a methanol pulse of 7 molecules per Brønsted acidic site at room temperature (RT) and a magnified region between 1050 and 800 is shown in the inset. $\neq$ (B) Magnified region of Fig. 1A. Artefact arising from the subtraction process is indicated with asterisk (Fig. 1A). ${ }^{19}$ The complete data set is presented in Fig. S2 of ESI. $\dagger$ The spectral resolution is around $20 \mathrm{~s}$.

to $\mathrm{C}-\mathrm{O}$ stretch of the methoxy species with the corresponding methyl rock band at $1185 \mathrm{~cm}^{-1,20,21}$ indicating the occurrence of methoxylation at RT. ${ }^{8}$ In the first few minutes of the reaction, the characteristic $\mathrm{P}-\mathrm{Q}-\mathrm{R}$ bands of gas phase methanol are observed at 1052, 1032 and $1012 \mathrm{~cm}^{-1}$ (Fig. 1B), resulting in a complex combination of bands between 980 and $1050 \mathrm{~cm}^{-1}$.

However, the $\mathrm{P}-\mathrm{Q}-\mathrm{R}$ bands disappear within the first five minutes of the reaction (as expected under He flow) and a new band attributable to $\mathrm{C}-\mathrm{O}$ stretch of the hydrogen bonded methanol appeared at $1004 \mathrm{~cm}^{-1}$ as evident from the red shift of the band position from 1012 to $1004 \mathrm{~cm}^{-1}$ (see Fig. 1A inset). The band at $1004 \mathrm{~cm}^{-1}$ extends well below $975 \mathrm{~cm}^{-1}$ enveloping the band at $990 \mathrm{~cm}^{-1}$. Likewise, the band at $1285 \mathrm{~cm}^{-1}$ could be a combination of different species. For example (see Fig. S3, ESI $\dagger$ ), the $\mathrm{C}-\mathrm{H}$ bending mode of either methanol or methoxy species can contribute to the spectrum between 1400 and $1250 \mathrm{~cm}^{-1}$, in addition to a potential contribution from the zeolite framework (see Fig. S1, ESI $\dagger$ ). Thus, the assignment of the band at $1285 \mathrm{~cm}^{-1}$ should be treated with caution. However, the assignment of band at $1185 \mathrm{~cm}^{-1}$ is straightforward (mainly to methyl rock of methoxy species) as there is neither gas phase methanol (see Fig. S3, ESI $\dagger$ ) nor $\mathrm{C}-\mathrm{H}$ bending modes of methoxy/methanol contributions. This is further corroborated by the fact that the band is symmetric (FWHM of $\approx 40 \mathrm{~cm}^{-1}$ ) and its relative intensity is similar to the corresponding $\mathrm{C}-\mathrm{O}$ stretch at $937 \mathrm{~cm}^{-1}$, which is opposite to the band at $1285 \mathrm{~cm}^{-1}$ (FWHM of $\approx 80 \mathrm{~cm}^{-1}$ ). The latter shows a sharp dip in intensity towards lower and a long extended tail towards higher wavenumbers. Also, a potential contribution to $1185 \mathrm{~cm}^{-1}$ from the zeolite framework that might arise on subtraction is unlikely as there are no significant framework bands below $1200 \mathrm{~cm}^{-1}$ (see Fig. S1, ESI $\dagger$ ).

The complexity of the low frequency methoxy bands requires us to seek additional evidence from the $\mathrm{C}-\mathrm{H}$ stretching region. The signature C-H stretching modes of the methoxy species at 2980 and $2863 \mathrm{~cm}^{-1}$ (Fig. 2A) ${ }^{9}$ are obscured by an intense triplet arising from protonated hydrogen bonded methanol species. ${ }^{12,19,20}$ Thus, the difference spectra derived from the earliest measurement and different stages of the reaction are compared in the inset of Fig. 2A. It is clear that the bands assignable to methoxy emerge at 2980 and $\approx 2875 \mathrm{~cm}^{-1}$, and 2967 and $2865 \mathrm{~cm}^{-1,4,9}$ which imply the occurrence of at least two types of methoxy species. The band at $\approx 2875 \mathrm{~cm}^{-1}$ corresponds to symmetric $\mathrm{C}-\mathrm{H}$ stretch enveloped by a broad feature between 2850-2880. In addition, all other features attributable to hydrogen bonded methanol are present (Fig. 1 and 2A). Clearly both methoxy and hydrogen bonded species immobilize methanol in ZSM-5 pores (between RT and $50{ }^{\circ} \mathrm{C}$ ). The immobility of methanol in the pores unambiguously explains the quasi-elastic neutron scattering (QENS) data. ${ }^{8,22-25}$

In line with the formation of methoxy species and protonated hydrogen bonded methanol, consumption of different hydroxyls is evident from negative bands above $3600 \mathrm{~cm}^{-1}$ (Fig. 1A and Fig. S4, ESI $\dagger$ ). Bands at 3615 and $3742 \mathrm{~cm}^{-1}$ are attributed to consumption of Brønsted acidic sites and silanol groups, respectively (Table S1, ESI $\dagger$ ). The consumption of silanol groups is consistent with the negative band at $871 \mathrm{~cm}^{-1}$ and with $\mathrm{C}-\mathrm{H}$ stretching bands at 2967 and $2865 \mathrm{~cm}^{-1}$. 9 The corresponding methyl rock band of the species falls at around $1150 \mathrm{~cm}^{-1}$, which is overlapped by the broad band at 1185. The consumption of Brønsted acidic hydroxyls is consistent with methoxy species reflected by bands at 937, 1185, 2875 and $2980 \mathrm{~cm}^{-1}$. These results confirm the occurrence of at least two types of methoxy species in ZSM-5, in line with earlier IR and INS studies. ${ }^{9,20}$ A similar observation is also reported by NMR and, significantly these methoxy species on ZSM-5 are not completely eroded upon hydrolysis with water at RT unlike on Y and SAPO-34, ${ }^{10}$ implying the unique intrinsic nature of active sites in ZSM-5. In the present study, the band at $3665 \mathrm{~cm}^{-1}$ is assigned to hydrolysed extra-framework $\mathrm{Al}(\mathrm{Al}-\mathrm{OH}) \cdot{ }^{19,20}$ Although the assignment of $3698 \mathrm{~cm}^{-1}$ band is not straight forward, it is safe to suggest the consumption of different hydroxyl groups (Table S1, ESI $\dagger$ ). The strength of acidity of these hydroxyls may decrease from 3600 to $3742 \mathrm{~cm}^{-1}$.

The formation of methoxy species is corroborated with MS data in Fig. 2B that show continuous evolution of water molecules during the reaction under He flow, indicating that the rate of reaction (eqn (1)) is very slow, as expected, under these reaction conditions. 

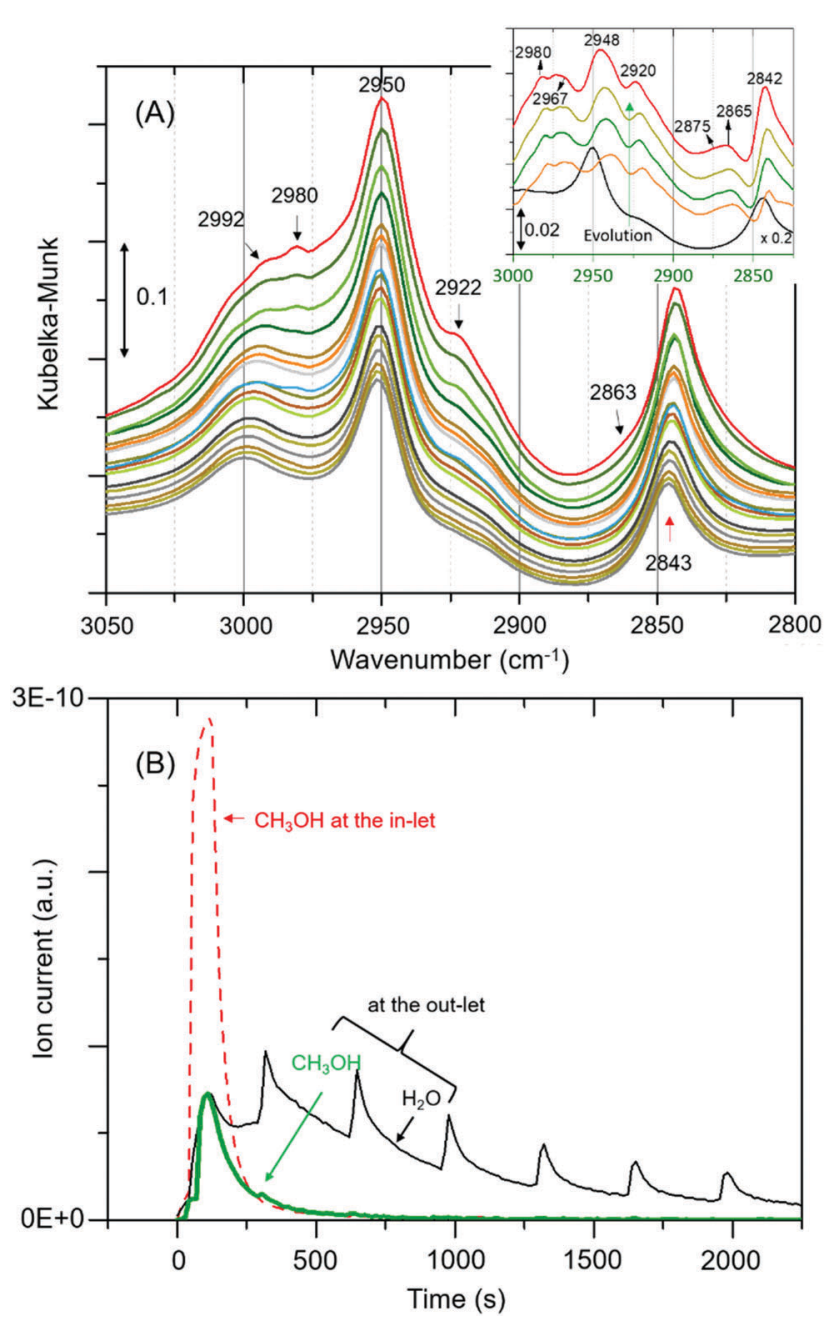

Fig. 2 (A) Magnified infrared spectra of Fig. 1A. Inset compares difference spectra of the earliest measurement and different stages of the reaction. (B) MS data, including the initial concentration of methanol (broken red line for reference).\& The repetitive water desorption peaks are in tandem with the heating tape (of the exhaust pipe) fluctuation $\left( \pm 20^{\circ} \mathrm{C}\right.$ ) cycle. As reaction proceeds water formation decreases due to a single methanol pulse that accounts for variations in water desorption peaks.

We note that the evolution of water demonstrates the occurrence of methoxylation at RT, and rules out displacement of any physisorbed water from the zeolite pores that would rather result in a fast and single step process, matching with the methanol MS profile. Overall around $80 \%$ methanol is converted as evident from the amount of methanol detected at the cell outlet.

The occurrence of room temperature methoxylation is further supported by analysing the methyl rock band at $1185 \mathrm{~cm}^{-1}$ and the water formation as a function of time in Fig. 3. The band at $1185 \mathrm{~cm}^{-1}$ grows rather rapidly and thereafter decreases gradually suggesting the conversion of methoxy species into other products. Given the reaction temperature, the gradual decrease in intensity of the band can be attributed to partial hydrolysis of methoxy species due to significant amounts of water formed during the methoxylation reaction. ${ }^{10}$

The assignment of vibrational frequencies is verified by DFT calculations using optimized structures of ZSM-5 with and
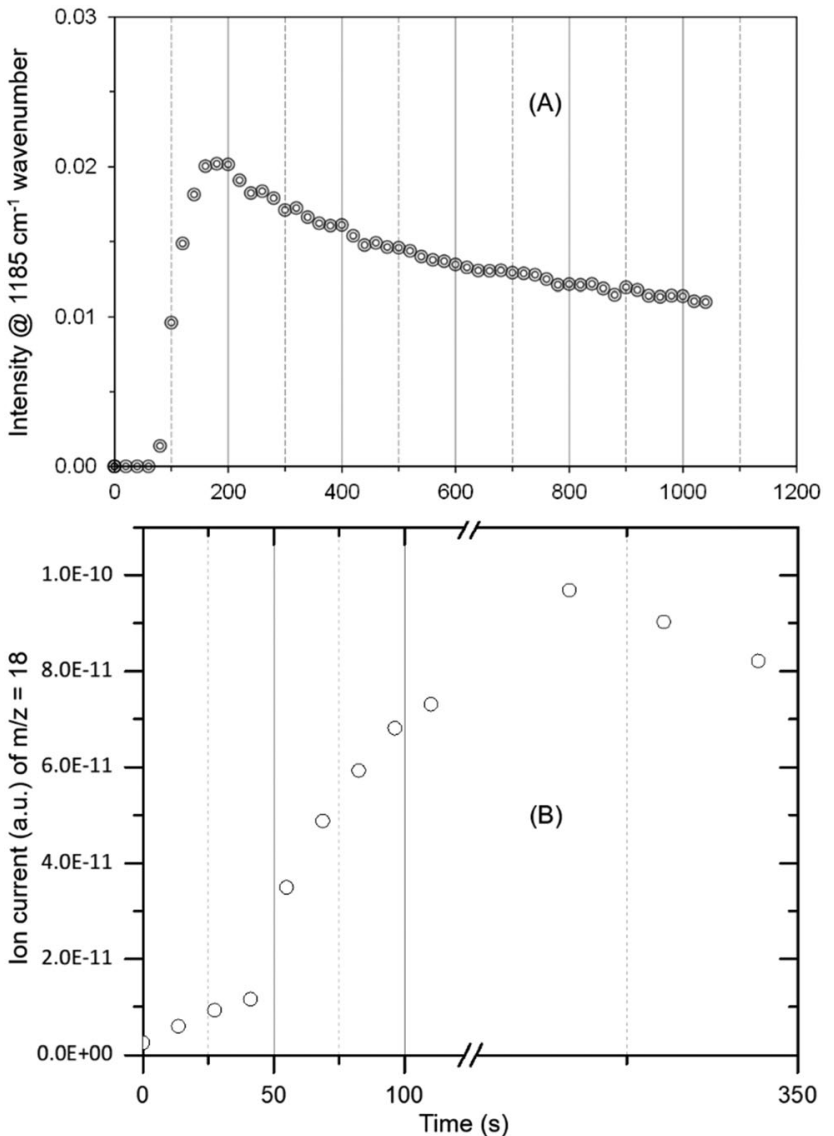

Fig. 3 The evolution of methoxy species reflected by the band at $1185 \mathrm{~cm}^{-1}$ (A) and water formation (B) as a function of time. The peak maximum is slightly delayed for MS data (B) as compared to DRIFTS (A) due to hampered water desorption in the exhaust pipe (refer Fig. 2) and more than one methoxy contribution to water formation. The latter could also explain slight differences in the evolution of methoxy and water profiles.

without adsorbed species (Table 1). The vibrational frequencies of methoxy or hydrogen bonded species are affected by the presence of a second molecule such as water or methanol molecule in the unit cell. A methoxy species at the Brønsted acidic site is calculated to have a C-O stretch at $945 \mathrm{~cm}^{-1}$ (structure A in Table 1) and a pair of methyl rock bands at 1138 and $1199 \mathrm{~cm}^{-1}$ (the latter is represented by structure B in Table 1). These methoxy bands are affected upon co-adsorption of either a methanol or water molecule in the unit cell.

A degree of fluctuations in calculated vibrational frequencies of the same species as a function of local environment of the zeolite unit cell imply the sensitivity and complexity of the IR bands. In line with this observation, C-O stretch and methyl rock of methoxy species in DRIFTS appeared between $920-950 \mathrm{~cm}^{-1}$, and 1130-1185 $\mathrm{cm}^{-1}$, respectively. Both experimental and calculated vibrational frequencies of gas phase methanol fall at higher wavenumbers as compared to than that of adsorbed species, making our assignments of the surface adsorbed species plausible.

To summarise, we have found clear and unambiguous evidence that with a saturation level of methanol loading in H-ZSM-5 pores, methoxylation takes place under ambient 
Table 1 Calculated vibrational frequencies for selected species and their structures

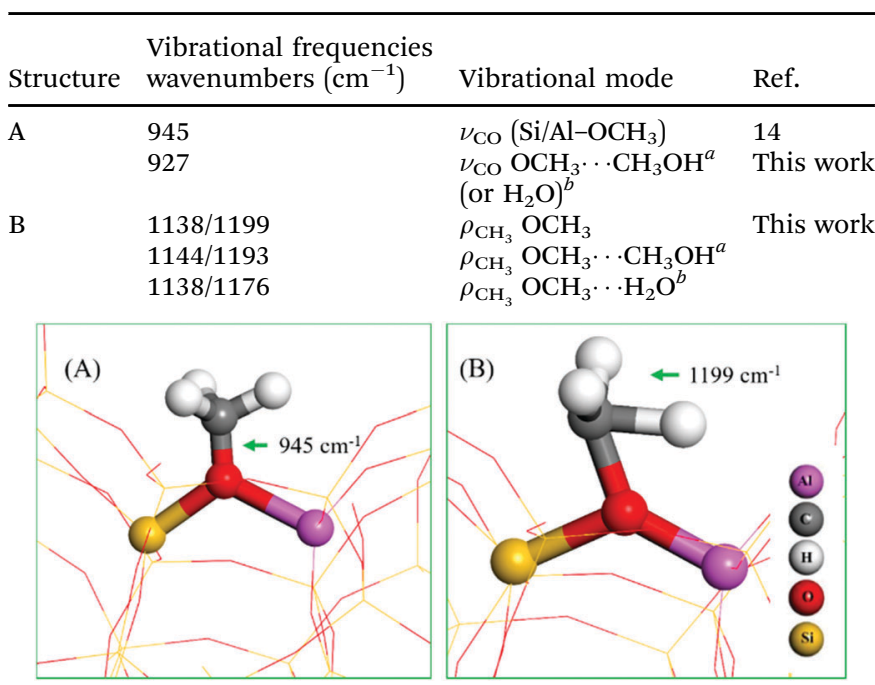

${ }^{a}$ Interaction of methanol with methoxy. ${ }^{b}$ Interaction of water with methoxy.

conditions along with a proportion of remaining hydrogen bonded species with protonated geometry, rationalising the apparent contradictions between earlier IR and neutron scattering data.

The UK Catalysis Hub is thanked for resources and support provided via our membership of the UK Catalysis Hub Consortium and funded by EPSRC (grants EP/I038748/1, EP/I019693/1, EP/ K014706/1, EP/K014668/1, EP/K014854/1, EP/K014714/1 and EP/ M013219/1). Via our membership of the UK's HEC Materials Chemistry Consortium, which is funded by EPSRC (EP/L000202), this work used the ARCHER UK National Supercomputing Service (www.archer.ac.uk). Johnson Matthey plc is thanked for the provision of the ZSM5. Dr A. J. O'Malley and Dr S. F. Parker are thanked for fruitful discussion.

\section{Conflicts of interest}

There are no conflicts to declare.

\section{Notes and references}

\$ The zeolite ZSM-5 $(\mathrm{Si} / \mathrm{Al} \approx 30)$ was obtained from Johnson Matthey and details are reported elsewhere. ${ }^{20,22}$ Prior to experiments, the zeolite was dehydrated under He flow $\left(100 \mathrm{ml} \mathrm{min}{ }^{-1}\right)$ at $500{ }^{\circ} \mathrm{C}$ for few hours and cooled to room temperature (RT). Methanol pulse (of $60 \mathrm{~s}$ ) experiment was conducted under the same He flow at RT with a pulse of 7 molecules per Brønsted acidic site that corresponds to the saturation level of loading under flow conditions. ${ }^{8,22}$ After a methanol pulse, the evolution of surface adsorbed species was monitored by DRIFTS, and reaction cell outlet by MS, for around 30 min under the same He flow. $\S$ The observed DRIFTS bands were verified by simulations. For this purpose, Density Functional Theory with a dispersion correction $(\mathrm{DFT}+\mathrm{D})$ was employed via the Vienna Ab-initio Simulation Package (VASP). ${ }^{26-28}$ The projector augmented wave (PAW) method and a planewave cut-off energy of $450 \mathrm{eV}$ was used with single $k$-point at the gamma point. The converged bulk energies were within $10^{-4} \mathrm{eV}$. The convergence criterion of $0.02 \mathrm{eV}^{-1}$ was used for the forces to optimise the structures. The Perdew-Burke-Ernzerhof (PBE) version of the generalized gradient approximation (GGA) was used for energy calculations and geometry optimizations. ${ }^{29}$ PBE exchange-correlation functional was used with Grimme's D2 correction scheme for dispersive interactions to allow the study of hydrogen bonding. ${ }^{30}$ The vibrational frequencies were calculated by finite differences to determine the second derivatives. A single unit cell of the MFI structure was used which has dimensions of $20.35 \AA \times$ $20.22 \AA \times 13.6 \AA$ containing $95 \mathrm{Si}$ atoms, $1 \mathrm{Al}$ atom and $192 \mathrm{O}$ atoms.

1 C. D. Chang and A. J. Silvestri, J. Catal., 1977, 47, 249.

2 I. M. Dahl and S. Kolboe, Catal. Lett., 1993, $20,329$.

3 V. van Speybroeck, K. Hemelsoet, L. Joos, M. Waroquier, R. G. Bell, C. Richard and A. Catlow, Chem. Soc. Rev., 2015, 44, 7044.

4 U. Olsbey, S. Svelle, K. P. Lillerud, Z. H. Wei, Y. Y. Chen, J. F. Li, J. G. Wang and W. B. Fan, Chem. Soc. Rev., 2015, 44, 7155.

5 F. Haase and J. Sauer, J. Phys. Chem., 1991, 98, 3083.

6 C. M. Zicovich-Wilson, P. Viruela and A. Corma, J. Phys. Chem., 1995, 99, 13224.

7 R. Hunter and G. J. Hutchings, J. Chem. Soc., Chem. Commun., 1985, 644.

8 A. J. O'Malley, S. F. Parker, A. Chutia, M. R. Farrow, I. Silverwood, V. G. Sakai, C. Richard and A. Catlow, J. Chem. Soc., Chem. Commun., 2016, 52, 2897.

9 T. R. Forester, S. T. Wong and R. F. Howe, J. Chem. Soc., Chem. Commun., 1986, 1611; T. R. Forester and R. F. Howe, J. Am. Chem. Soc., 1987, 109, 5076.

10 W. Wang, A. Buchholz, M. Seiler and M. Hunger, J. Am. Chem. Soc., 2003, 125, 15260.

11 J. Van der Mynsbrugge, S. L. C. Moors, K. De Wispelaere and V. Van Speybroeck, ChemCatChem, 2014, 6, 1906.

12 A. Zecchina, S. Bordiga, G. Spoto, D. Scarano, G. Spano and F. Geobaldo, J. Chem. Soc., Faraday Trans., 1996, 92(23), 4863.

13 P. E. Sinclair and C. R. A. Catlow, J. Chem. Soc., Faraday Trans., 1996, 92(12), 2099.

14 P. E. Sinclair, C. Richard and A. Catlow, J. Chem. Soc., Faraday Trans., 1997, 93(2), 333.

15 D. Lesthaeghe, V. Van Speybroeck, G. B. Marin and M. Waroquier, Angew. Chem., Int. Ed., 2006, 45, 1714.

16 S. R. Blaszkowski and R. A. van Santen, J. Phys. Chem. B, 1997, $101,2292$.

17 E. Sandre, M. C. Payne and J. D. Gale, J. Chem. Soc., Chem. Commun., $1998,2445$.

18 M. C. Payne, M. Hytha, I. Stich, J. D. Gale and K. Terakura, Microporous Mesoporous Mater., 2001, 48, 375.

19 B.-T. L. Bleken, L. Mino, F. Giordanino, P. Beato, S. Svelle, K. P. Lillerud and S. Bordiga, Phys. Chem. Chem. Phys., 2013, 15, 13363.

20 Suwardiyanto, R. F. Howe, E. K. Gibson, C. Richard A. Catlow, A. Hameed, J. McGregor, P. Collier, S. F. Parker and D. Lennon, J. Chem. Soc. Faraday Discuss., 2017, 197, 447.

21 M. El-Roz, P. Bazin, M. Daturi and F. T-Starzyk, Phys. Chem. Chem. Phys., 2015, 17, 11277.

22 S. K. Matam, A. J. O'Malley, C. Richard A. Catlow, Suwardiyanto, P. Collier, A. P. Hawkins, A. Zachariou, D. Lennon, I. Silverwood, S. F. Parker and R. F. Howe, Catal. Sci. Technol., 2018, 8, 3304.

23 H. Jobic, A. Renouprez, M. Bec and C. Poinsignon, J. Phys. Chem., 1986, 90, 1059.

24 N. M. Gupta, D. Kumar, V. Kamble, S. Mitra, R. Mukhopadhyay and V. Kartha, J. Phys. Chem. B, 2006, 110, 4815.

25 S. Mitra, V. S. Kamble, A. K. Tripathi, N. M. Gupta and R. Mukhopadhyay, Pramana - J. Phys., 2004, 63, 443.

26 G. Kresse and J. Hafner, Phys. Rev. B: Condens. Matter Mater. Phys., 1993, 47, 558.

27 P. E. Blochl, Phys. Rev. B: Condens. Matter Mater. Phys., 1994, 50, 17953.

28 G. Kresse and J. Furthmuller, Phys. Rev. B: Condens. Matter Mater. Phys., 1996, 54, 11169.

29 J. P. Perdew, K. Burke and M. Ernzerhof, Phys. Rev. Lett., 1996, 77,3865 .

30 S. Grimme, J. Comput. Chem., 2006, 27, 1787. 